\title{
Investigation of Social Support Perception and Self-Esteem as Predictors of Psychological Resilience of Parents Who Have Children with Special Educational Needs
}

\section{Erkan Karaman $^{1}$ Erkan Efilti ${ }^{2 \rtimes}$}

'Ministry of Education Special Education Teacher, Osmaniye, Turkey Email:erkankaraman2015@gmail.com Tel: +905076521428

${ }^{2}$ Necmettin Erbakan University, Ahmet Keleşoğlu Education Faculty, Special Education Department, Konya, Turkey

Email:efilti71@gmail.com Tel: +905414720301

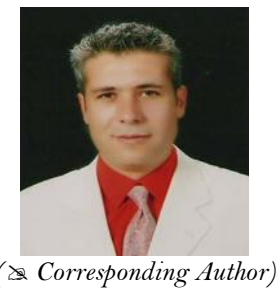

\begin{abstract}
This study was conducted to examine the perceived social support and self-esteem as predictors of the psychological resilience of the parents who have children with special educational needs. This study aimed to reveal the relationship between the psychological resilience of the parents who had children with special educational needs and the level of social support they perceived and their self-esteem levels. This research is a correlation study in relational screening model. 235 parents (205 females and 30 males) participated in this study. Personal Information Form, Resilience Scale for Adults, Aricak Self-Esteem Scale and Revised Parental Social Support Scale were used as data collection instruments. In the evaluation of the data number, percentage, mean and standard deviation were used as descriptive statistical methods. The t-test was used to compare quantitative continuous data between two independent groups, and one way Anova test was used to compare quantitative continuous data between more than two independent groups. Scheffe test was used as a complementary post-hoc analysis to determine the differences after the Anova test. According to the research results, there is a significant relationship between psychological resilience, perceived social support and self-esteem. Perceived social support and self-esteem variables predicted the psychological resilience. The results of the research were discussed in the relevant literature.
\end{abstract}

Keywords: Psychological resilience, Perceived social support, Self-Esteem, Special education, Parent perception, Disabled children.

Citation | Erkan Karaman; Erkan Efilti (2019). Investigation of Social Support Perception and Self-Esteem as Predictors of Psychological Resilience of Parents Who Have Children with Special Educational Needs. Asian Journal of Education and Training, 5(1): 112-120.

History

Received: 29 October 2018

Revised. 6 December 2018

Acepted: 8 January 2019

2019

Published: 2 February 2019

Licensed: This work is licensed under a Creative Commons Attribution 3.0 License $(\mathrm{coc})$

Publisher: Asian Online Journal Publishing Group
Contribution/Acknowledgement: This study was prepared by Erkan Karaman under the supervision of Dr. Erkan Efilti as a master's thesis in the Department of Special Education at Educational Sciences Institute of Konya Necmettin Erbakan University

Funding: This study received no specific financial support

Competing Interests: The authors declare that they have no conflict of interests.

Transparency: The authors confirm that the manuscript is an honest, Transparency: The authors confirm that the manuscript is an honest,
accurate, and transparent account of the study was reported; that no vital accurate, and transparent account of the study was reported; that no vital
features of the study have been omitted; and that any discrepancies from the features of the study have been omitte
study as planned have been explained.

Ethical: This study follows all ethical practices during writing.

\section{Contents}

1. Introduction ..........................113

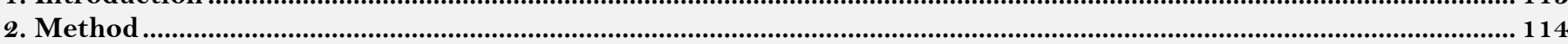

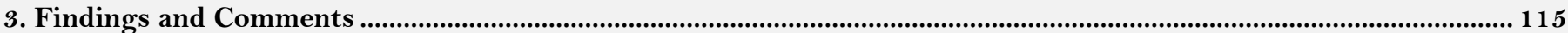

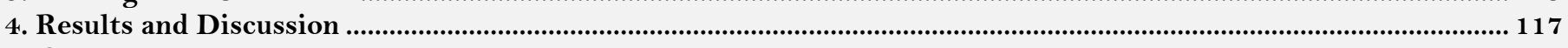

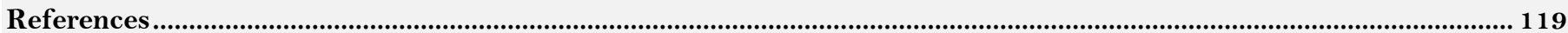




\section{Introduction}

Psychological resilience is defined as an active process that enables a stronger emergence, development in the case of crisis and durability when faced with a unfavorable situation (Walsh, 2006; as cited in Kaner et al. (2011)).

According to Garmezy (1993) a leading researcher in psychological resilience studies, psychological resilience is hidden in the strength of recovery and it is the ability of the individual to return to the existing abilities and behaviors that existed before the stressful event (Bayrakli, 2010).

In another definition, Fraser et al. (1999) describe psychological resilience as "the ability to gain positive and unexpected success under difficult conditions and adapt to unusual conditions and situations" (Gizir, 2007).

Psychological resilience includes adaptation to the change in the individual's life, when faced with an unfavorable situation, in the process resulting from the interaction of risk factors and protective factors (Karairmak, 2006).

The components of psychological resilience encountered in many definitions are grouped under three headings: risk factors, protective factors and positive outcomes (Coleman and Hagell, 2007). Masten (2001) in his research stated that individuals must be exposed to an explainable risk to talk about psychological resilience. Risk factors are discussed in three groups as individual related risk factors related, family related risk factors and social risk factors (Rutter, 2006). Children who live in conditions where there is no significant risk situation can be considered as "adequate" or "competent", "compliant" or just "normal", but this cannot be mentioned in terms of "psychological resilience" for children or adolescents (Masten and Reed, 2002). Risk factors are segmented as individual related risk factors, family related risk factors and social risk factors. Risk factors related to the person are as follows; low intelligence, anxious temperament, health problems, low self-esteem, low self-esteem, inability to use effective coping mechanisms, low self-control ability, inability to express themselves effectively, aggressive personality structure and incompatible behaviors. Family related risk factors include familial diseases, divorcing of parents, having one parent, lack of healthy relationships between parents and child, hard or inconsistent discipline, negative relationships among siblings, domestic violence, family neglect and abuse. Social risk factors include low socioeconomic level, inadequacy of home, school or other services, lack of social positive role models, substance use, social incidents such as immigration and unemployment and presence of violence in the environment (Ülker, 2012).

Protective factors may include individual characteristics, familial and environmental factors, or conditions resulting from the interaction of these dimensions. It is important to determine how protective factors reduce, stop or even prevent the risk, regardless of the extent to which these dimensions exist. Therefore, the examination of individual, familial and environmental characteristics of protective individuals in psychological resilience research has a great importance in terms of explaining why some individuals at risk have more healthy and successful adaptations than others (Greene and Conrad, 2002; as cited in Gizir (2007)).

Other individual factors determined to be associated with psychological resilience are intelligence, easy temperament, internal locus of control, high self-esteem, and self-efficacy, self-awareness, autonomy, problemsolving ability, optimism and hope, and social competence (Gizir, 2007).

Familial protective factors include the high level income of the family, the ability of parents to exhibit good parental characteristics, the close relationship between the parents and the strong family ties. Factors such as positive and intimate relationship with a non-family adult, having good education in schools and having a social environment are protective environmental factors (Masten and Coasworth, 1998; as cited in Bildirici (2014)).

Compliance or positive results, which are another dimension of psychological resilience, imply that the individual turns back to the old psychological well-being and adjusts to the new situation. Masten and Reed (2002) stated that these positive results were the fulfillment of their developmental tasks, academic success, positive social relations/social competence, avoiding criminal behavior, psychological health, lack of emotional problems or symptoms, happiness, school attendance, age-appropriate sports, social assistance activities participation, taking part in extracurricular activities, conducting behaviors according to the rules, making friends and being close friendship, lack of psychopathology, being a psychosocial harmony compound, accepting itself and being compatible, life satisfaction and well being (as cited in Ülker (2012)).

Social support can be considered as providing services through individuals and/or institutions that can reduce the negative consequences of the stressing situation in general and improve adaptive competence (Kaner, 2010).

According to Lambert et al. (1989) social support protects the individual from the stressful effects of the variables in his/her life and increases his/her belief that the individual is loved and accepted by the society. Another definition related to social support is satisfying the needs of the individual such as belonging, love, appreciation, self-realization as a result of the interaction with other individuals (Cattık, 2015).

According to Guralnick et al. (2008) social support can be provided by the society in which the individual is living, his/her friends, wife and extended family. Social support has an important place in terms of ensuring the satisfaction of the need for each individual in terms of life, as well as strengthening, preserving and sustaining the bio-psychosocial well-being (Özkan, 2002; as cited in Sivrikaya (2012)). It is known that social support has an impact on the occurrence, course and duration of many physical or mental illnesses. It is known that social support can prevent the formation of stress, and change the way the event is perceived when stress is present, it helps $\mathrm{him} /$ her in situations where the person is forced, and affects ways of coping (Sorias, 1992; as cited in Aslan (2010)) House (1981) gathered the social support in four classes: emotional and social support, instrumental support, information support and evaluation support (Cattık, 2015).

Rosenberg defined self-respect as a positive and negative attitude towards the individual. According to him, self-esteem is the result of self-evaluation of the individual. The individual's judgment as a result of his/her selfassessment is decisive for the level of self-esteem. Self-esteem is an individual's assessment of his or her worth related self-concept (Saban, 2010).

According to Yörükoğlu (1987) self-esteem is a state of appreciation which emerges approving the self-concept as a result of individual's assessment. Chrzanowski (1981) argues that self-esteem is a positive image of the person, based on a good evaluation of his/her competences and powers in the broadest sense. Some aspects of self-esteem develop on the natural characteristics of the person, such as intelligence, appearance and body structure (Chzanowski, 1980; as cited in Satılmış and Seber, 1989; as cited in Demir (2010)). 
Having a child with special educational needs is a risk factor for the psychological health of parents. The factors affecting the psychological resilience of the parents who need to have special education are important for the parents and children who need special education. When the literature is examined, it is seen that the research has originality in terms of the lack of any research in which whether the perception of social support and the selfesteem predict the psychological resilience of the parents who need special education.

\subsection{Purpose of the Study}

The purpose of the study is to examine whether the perceived social support and self-esteem levels predict the psychological resilience levels of parents who have children with special educational needs.

\subsection{Sub Purposes}

In the study, the answers were sought to the following questions:

1. Is there a relationship between the psychological resilience, perceived social support and self-esteem levels of the parents who have children with special educational needs?

2. Do the perceived social support levels of parents who have children with special educational needs predict their psychological resilience levels?

3. Do the self-esteem levels of parents who have children with special educational needs predict their psychological resilience levels?

4. Do the perceived social support and self-esteem levels of parents who have children with special educational needs predict their psychological resilience levels?

\section{Method}

In this study, it was aimed to examine social support perception and self-esteem as the predictors of psychological resilience of the parents who had children with special educational needs. This research is a correlation study in the relational survey model.

\subsection{Population and Sample}

The population of the research is all parents who have children with special educational needs. The sample of this study consisted of randomly selected 235 participants (205 mothers and 30 fathers) from four different private special education and rehabilitation centers serving in Osmaniye.

\subsection{Data Collection Instruments}

Personal Information Form, Resilience Scale for Adults, Arıcak Self-Esteem Scale and Revised Parental Social Support Scale were used as data collection instruments.

\subsubsection{Personal Information Form}

The personal information form was created to record the personal information of mothers or fathers who participated in the research.

\subsubsection{Resilience Scale for Adults}

The Resilience Scale for Adults developed by Friborg et al. (2003) is consisted five sub-dimensions: structured style, family cohesion, personal power, social competence and social resources. The later study (Friborg et al., 2005) shows that the six-dimensional structure of the scale explains the psychological resilience model better. Friborg et al. (2005) divided the "personal power" dimension into two as "self-perception" and "planned future", and a total six-dimensional structure emerged (Basim and Cetin, 2011).

The sub-dimensions and items of the scale were determined as follows: structured style $(3,9,15,21)$, planned future $(2,8,14,20)$, family cohesion $(5,11,17,23,26,32)$, self-perception $(1,7,13,19,28,31)$, social competence $(4,10,16,22,25,29)$, and social resources $(6,12,18,24,27,30,33)$.

\subsubsection{Revised Parental Social Support Scale}

The Revised Parental Social Support Scale, Family Social Support Scale-FSSS (Kaner, 2003) was created by reexamining the qualitative dimension of social support, according to the related literature. As a result of the studies conducted to determine the validity of the Revised Parent Social Support Scale, a scale consisting of four factors and 28 items was obtained.

\subsubsection{Arucak Self-Esteem Scale}

The Self-Esteem Scale developed by Aricak (1999) is a five-point Likert-type attitude scale. Studies of various theorists and scientists were examined in the preparation of the scale. Later on, a pool of substances consisting of positive and negative expressions about self-esteem was created with the studies carried out with the students of the Primary School Teaching Department. These statements were presented to the evaluation of the experts who work in psychology and psychological counseling. Reliability and validity studies were carried out with the items obtained, modified and added in the light of the opinions of the experts and as a result a scale consisting of 32 items was obtained.

\subsection{Data Analysis}

The data obtained from the study were analyzed by using SPSS (Statistical Package for Social Sciences) for Windows 22.0 program. Number, percentage, mean and standard deviation were used as descriptive statistical methods in the evaluation of the data.

The t-test was used to compare quantitative continuous data between two independent groups, and One way Anova test was used to compare quantitative continuous data between more than two independent groups. Scheffe 
test was used as a complementary post-hoc analysis to determine the differences after the Anova test. Pearson correlation and regression analysis were applied to the continuous variables of the study. The findings were evaluated at 95\% confidence interval and 5\% significance level.

In this study, the reliability of the Resilience Scale for Adults was found to be Cronbach's Alpha=0,889. The reliability of the Parental Social Support Scale was found to be Cronbach's Alpha=0,892. The reliability of the Selfesteem Scale was found to be Cronbach's Alpha=0,854.

\section{Findings and Comments}

In this section, the findings of the analysis of the data collected by the parents who participated in the research for the solution of the research problem are included. Explanations and comments were made based on the findings.

\subsection{Findings on the Relationship between Perceived Social Support, Self-Esteem and Psychological Resilience Levels of Parents Who Have Children with Special Educational Needs}

The study aimed to answer the question "Is there a relationship between the psychological resilience, perceived social support, and self-esteem levels of the parents who have children with special educational needs? The findings related to the question were presented in Table 1.

Table-1. Correlation Relationship between Perceived Social Support, Self-Esteem and Psychological Resilience Levels of Parents Who Have Children with Special Educational Needs

\begin{tabular}{|c|c|c|c|c|c|c|c|c|}
\hline & & 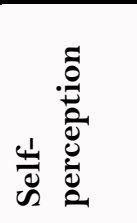 & 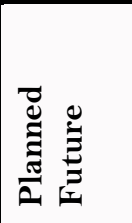 & 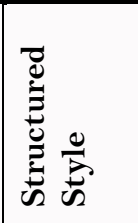 & 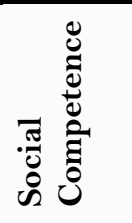 & 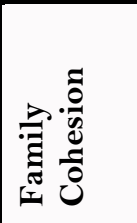 & $\begin{array}{rl} & 0 \\
0 & 0 \\
: \frac{\pi}{0} & 0 \\
0 & 0 \\
0 & 0\end{array}$ & 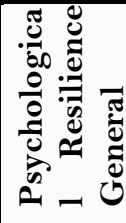 \\
\hline \multirow{2}{*}{ Social Cohesion Support } & $r$ & $0,417 * *$ & $0,472^{* *}$ & $0,335^{* *}$ & $0,228 * *$ & $0,437 * *$ & $0,269^{* *}$ & $0,477 * *$ \\
\hline & $\mathrm{p}$ & $\mathrm{O}$ & $\mathrm{O}$ & 0 & $\mathrm{O}$ & 0 & $\mathrm{O}$ & $\mathrm{O}$ \\
\hline \multirow{2}{*}{ Information Support } & $r$ & $0,347 * *$ & $0,413^{* *}$ & $0,236 * *$ & $0,143^{*}$ & $0,407^{* *}$ & $0,194^{* *}$ & $0,404^{* *}$ \\
\hline & $\mathrm{p}$ & 0 & $\mathrm{O}$ & $\mathrm{O}$ & 0,028 & $\mathrm{O}$ & 0,003 & $\mathrm{O}$ \\
\hline \multirow{2}{*}{ Emotional Support } & $\mathrm{r}$ & $0,338^{*} *$ & $0,437 * *$ & $0,271 * *$ & $0,158^{*}$ & $0,405^{* *}$ & $0,226^{* *}$ & $0,415^{* *}$ \\
\hline & $\mathrm{p}$ & 0 & o & 0 & 0,015 & 0 & O & 0 \\
\hline \multirow{2}{*}{ Care Support } & $\mathrm{r}$ & $0,268 * *$ & 0,341 ** & $0,162 *$ & 0,048 & $0,372 * *$ & 0,1 & $0,299 * *$ \\
\hline & $\mathrm{p}$ & 0 & 0 & 0,013 & 0,463 & 0 & 0,125 & 0 \\
\hline \multirow{2}{*}{$\begin{array}{l}\text { Parental Social Support } \\
\text { Total }\end{array}$} & $r$ & $0,374^{* *}$ & $0,450^{* *}$ & $0,283^{* *}$ & $0,172^{* *}$ & $0,431^{* *}$ & $0,226^{* *}$ & $0,437 * *$ \\
\hline & $\mathrm{p}$ & $\mathrm{O}$ & $\mathrm{O}$ & 0 & 0,008 & 0 & $\mathrm{O}$ & 0 \\
\hline \multirow{2}{*}{ Self-esteem } & $\mathrm{r}$ & $0,553 * *$ & $0,549 * *$ & $0,417 * *$ & $0,449 * *$ & $0,410^{* * *}$ & $0,430 * *$ & $0,633^{* *}$ \\
\hline & $\mathrm{p}$ & $\mathrm{O}$ & $\mathrm{O}$ & $\mathrm{O}$ & $\mathrm{O}$ & $\mathrm{O}$ & $\mathrm{O}$ & 0 \\
\hline
\end{tabular}

Source: Obtained from analysis of data. ${ }^{*} \mathrm{p}<0,05$

When Table 1 is examined, it is seen that there are significant relationships between psychological resilience general scores and psychological resilience subscale scores, social support level total scores, perceived social support subscale scores, and self-esteem scores of parents who have children with special educational needs.

There is a weak and positive correlation between the psychological resilience overall scores and perceived social support scores of the parents who have children with special educational needs. There is a positive and significant correlation between the psychological resilience overall scores and the self-esteem scores of the parents who have children with special educational needs. There is a weak and positive correlation between the perceived social support total scores and self-esteem scores of the parents who have children with special educational needs.

\subsection{Findings on the Perceived Social Support Level as a Predictor of Psychological Resilience Level of Parents Who Have Children with Special Educational Needs}

As the second sub-objective of the research, Table 2 shows whether the social support perception scores of the parents who have children with special educational needs are predictive of their psychological resilience levels.

In order to determine whether the perceived social support scores of the parents who have children with special educational needs were predictive of the psychological resilience scores, general and sub-dimension regression analyzes were performed in Table 2 .

As a result of the regression analysis, the perceived social support total scores were found to be significant but weak in predicting the general levels of psychological resilience. $\left(\mathrm{R}^{2}=0,188\right)$.

As a result of regression analysis, statistically significant differences were found between the sub-dimensions of psychological resilience (self-perception, planned future, structured style, social competence, family cohesion and social resources) and sub-dimensions of parental social support (social cohesion support, information support, emotional support and care support). While the predictive power between the sub-dimensions of self-perception, structured style, social competence, family cohesion and social resources and sub-dimensions of social cohesion support, information support, emotional support and care support was found to be weak, a strong predictive power was found between the sub-dimension of planned future and sub-dimensions of social cohesion support, information support, emotional support and care support $\left(\mathrm{R}^{2}=0,222\right)$. 
Table-2. Findings on the Perceived Social Support Level as s Predictor Level of Psychological Resilience Level of Parents Who Have Children with Special Educational Needs

\begin{tabular}{|c|c|c|c|c|c|c|}
\hline Dependent Variable & 及 & $\mathrm{t}$ & $\mathrm{p}$ & $\mathbf{F}$ & Model (p) & $\mathbf{R}^{2}$ \\
\hline \multirow{2}{*}{ Psychological Resilience General } & 2,435 & 14,447 & 0,000 & \multirow{2}{*}{55,058} & \multirow{2}{*}{$\mathrm{O}$} & \multirow{2}{*}{0,188} \\
\hline & PSST 0,015 & PSST 7,420 & PSST 0,000 & & & \\
\hline \multirow{5}{*}{ Self-perception } & 2,367 & 10,193 & 0,000 & \multirow{5}{*}{13,48} & \multirow{5}{*}{0} & \multirow{5}{*}{$0,17 €$} \\
\hline & SCS 0,075 & SCS 4,222 & SCS 0,000 & & & \\
\hline & IS 0,016 & IS 0,396 & IS 0,692 & & & \\
\hline & $\mathrm{ES}-0,017$ & $\mathrm{ES}-0,596$ & ES 0,552 & & & \\
\hline & CS -0,063 & $\mathrm{CS}-1,673$ & CS 0,096 & & & \\
\hline \multirow{5}{*}{ Planned Future } & 1,335 & 5,083 & 0,000 & \multirow{5}{*}{17,703} & \multirow{5}{*}{0} & \multirow{5}{*}{0,222} \\
\hline & SCS 0,070 & SCS 3,460 & SCS 0,001 & & & \\
\hline & IS -0,023 & IS -0,523 & IS 0,601 & & & \\
\hline & ES 0,044 & ES 1,353 & ES 0,178 & & & \\
\hline & CS -0,063 & $\mathrm{CS}-1,495$ & CS o, 136 & & & \\
\hline \multirow{5}{*}{ Structured Style } & 2,579 & 10,234 & 0,000 & \multirow{5}{*}{10,644} & \multirow{5}{*}{0} & \multirow{5}{*}{$0,14 \%$} \\
\hline & SCS 0,082 & SCS 4,244 & SCS 0,000 & & & \\
\hline & IS -0,060 & IS - 1,400 & IS 0,163 & & & \\
\hline & ES 0,036 & ES 1,155 & ES 0,249 & & & \\
\hline & CS -0,097 & $\mathrm{CS}-2,375$ & CS 0,184 & & & \\
\hline \multirow{5}{*}{ Social Competence } & 3,113 & 12,775 & 0,000 & \multirow{5}{*}{7,002} & \multirow{5}{*}{0} & \multirow{5}{*}{0,093} \\
\hline & SCS 0,070 & SCS 3,756 & SCS 0,000 & & & \\
\hline & IS -0,016 & IS -0,397 & IS 0,691 & & & \\
\hline & ES 0,009 & ES 0,298 & ES 0,766 & & & \\
\hline & CS -0,122 & $\mathrm{CS}-3,107$ & CS 0,213 & & & \\
\hline \multirow{5}{*}{ Family Cohesion } & 2,091 & 8,713 & 0,000 & \multirow{5}{*}{13,666} & \multirow{5}{*}{0} & \multirow{5}{*}{$0,17 \varepsilon$} \\
\hline & SCS 0,045 & SCS 2,458 & SCS 0,015 & & & \\
\hline & IS 0,009 & IS 0,211 & IS 0,833 & & & \\
\hline & ES 0,005 & ES 0,156 & ES 0,876 & & & \\
\hline & $\mathrm{CS} 0,007$ & CS 0,186 & CS 0,853 & & & \\
\hline \multirow{5}{*}{ Social Resources } & 3,534 & 21,582 & 0,000 & \multirow{5}{*}{7,914} & \multirow{5}{*}{0} & \multirow{5}{*}{0,106} \\
\hline & SCS 0,041 & SCS 3,250 & SCS 0,001 & & & \\
\hline & IS - 0,021 & IS -0,765 & IS 0,445 & & & \\
\hline & ES 0,027 & ES 1,315 & ES 0,190 & & & \\
\hline & CS -0,079 & $\mathrm{CS}-3,002$ & CS 0,298 & & & \\
\hline
\end{tabular}

Source: Obtained from analysis of data. ${ }^{*} \mathrm{p}<0,05$

Abbreviations in Table 2: PSST-Parents Social Support Total, SCS-Social Cohesion Support, IS- Information Support, ES- Emotional Support, CS- Care Support

Social cohesion support increase the levels of self-perception, planned future, structured style, social competence, family cohesion and social resources; information support emotional support and care support do not affect them.

3.3. Findings on the Self-Esteem Level as a Predictor of Psychological Resilience Level of Parents Who Have Children with Special Educational Needs

Table 3 shows whether the self-esteem scores of the parents who have children with special educational needs are predictive of their psychological resilience levels.

As a result of regression analysis to determine the causal relationship between self-esteem and psychological resilience, the difference was statistically significant $(\mathrm{F}=155,989 ; \mathrm{p}=0,000<0.05)$.

Table-3. Findings on the Self-Esteem Level as a Predictor of Psychological Resilience Level of Parents Who Have Children with Special Educational Needs

\begin{tabular}{|c|c|c|c|c|c|c|c|}
\hline Dependent Variable & Independent Variable & B & $\mathbf{t}$ & p & $\mathbf{F}$ & Model (p) & $\mathbf{R}^{2}$ \\
\hline \multirow{2}{*}{$\begin{array}{l}\text { Psychological } \\
\text { Resilience-General }\end{array}$} & Invariant & 0,365 & 1,378 & 0,17 & \multirow{2}{*}{155,989} & \multirow{2}{*}{0,000} & \multirow{2}{*}{0,398} \\
\hline & Self-esteem & 0,029 & 12,49 & 0,000 & & & \\
\hline \multirow{2}{*}{ Self-perception } & Invariant & $-0,205$ & $-0,533$ & 0,595 & \multirow{2}{*}{102,595} & \multirow{2}{*}{0,000} & \multirow{2}{*}{0,303} \\
\hline & Self-esteem & 0,034 & 10,129 & 0,000 & & & \\
\hline \multirow{2}{*}{ Planned Future } & Invariant & $-1,257$ & $-2,804$ & 0,005 & \multirow{2}{*}{100,486} & \multirow{2}{*}{0,000} & \multirow{2}{*}{0,298} \\
\hline & Self-esteem & 0,039 & 10,024 & 0,000 & & & \\
\hline \multirow{2}{*}{ Structured Style } & Invariant & 0,498 & 1,118 & 0,265 & \multirow{2}{*}{48,903} & \multirow{2}{*}{0,000} & \multirow{2}{*}{0,17} \\
\hline & Self-esteem & 0,027 & 6,993 & 0,000 & & & \\
\hline \multirow{2}{*}{ Social Competence } & Invariant & 0,479 & 1,163 & 0,246 & \multirow{2}{*}{58,709} & \multirow{2}{*}{0,000} & \multirow{2}{*}{0,198} \\
\hline & Self-esteem & 0,027 & 7,662 & 0,000 & & & \\
\hline \multirow{2}{*}{ Family Cohesion } & Invariant & 0,767 & 1,763 & 0,079 & \multirow{2}{*}{46,989} & \multirow{2}{*}{0,000} & \multirow{2}{*}{0,164} \\
\hline & Self-esteem & 0,026 & 6,855 & 0,000 & & & \\
\hline \multirow{2}{*}{ Social Resources } & Invariant & 1,99 & 7,068 & 0,000 & \multirow{2}{*}{52,829} & \multirow{2}{*}{0,000} & \multirow{2}{*}{0,181} \\
\hline & Self-esteem & 0,018 & 7,268 & 0,000 & & & \\
\hline
\end{tabular}

Source: Obtained from analysis of data. ${ }^{*} \mathrm{p}<0,05$ 
The relationship between self-esteem variables as a determinant of the general level of psychological resilience (explanatory power) was found to be strong $\left(\mathrm{R}^{2}=0,398\right)$. The level of self-esteem of parents increases the overall level of psychological resilience $(\beta=0,029)$.

Regression analysis to determine the cause-effect relationship between self-esteem and self-esteem was statistically significant $(\mathrm{F}=102,595 ; \mathrm{p}=0,000<0.05)$. The relationship between self-esteem variables as a determinant of self-perception was found to be strong $\left(\mathrm{R}^{2}=0,303\right)$. The level of self-esteem of the parents increases the level of self-perception $(\beta=0,034)$.

Regression analysis to determine the cause-effect relationship between self-esteem and structural style was statistically significant $(\mathrm{F}=48,903 ; \mathrm{p}=0,000<0.05)$. As a determinant of the structured style, its relationship with self-esteem variables (weakness of expression) was found to be weak $\left(\mathrm{R}^{2}=0,170\right)$. The level of parents' self-esteem increases the level of structural style $(\beta=0,027)$.

Regression analysis to determine the cause-effect relationship between self-esteem and social competence was found to be statistically significant $(\mathrm{F}=58,709 ; \mathrm{p}=0,000<0.05)$. The relationship between self-esteem variables as a determinant of the level of social competence (explanatory power) was found to be weak $\left(\mathrm{R}^{2}=0,198\right)$. The level of self-esteem of the parents increases the level of social competence $(\beta=0,027)$.

Regression analysis to determine the cause-effect relationship between self-esteem and family harmony was found statistically significant $(\mathrm{F}=46,989 ; \mathrm{p}=0,000<0.05)$. The relationship between self-esteem variables as a determinant of the level of family harmony (explanatory power) was found to be weak $\left(\mathrm{R}^{2}=0,164\right)$. The level of parents' self-esteem increases the level of family harmony $(\beta=0,026)$.

Regression analysis to determine cause-effect relationship between self-esteem and social resources was found to be statistically significant $(\mathrm{F}=52,829 ; \mathrm{p}=0,000<0.05)$. As a determinant of the level of social resources, the relationship between self-esteem variables (explanatory power) was found to be weak $\left(\mathrm{R}^{2}=0,182\right)$. The level of selfesteem of the parents increases the level of social resources $(\beta=0,018)$.

\subsection{Findings on the Self-Esteem and Perceived Social Support Levels as Predictors of Psychological Resilience Levels of Parents Who Have Children with Special Educational Needs}

Table 4 shows whether the perceived social support and self-esteem scores of the parents who have children with special educational needs are predictive of their psychological resilience levels.

Table-4. Hierarchical Effect of Social Support and Self-Esteem of Parents Who Have Children with Special Educational Needs on Their Psychological Resilience

\begin{tabular}{|c|c|c|c|c|c|c|c|c|}
\hline Dependent Variable & & Independent Variable & B & $\mathbf{t}$ & $\mathbf{p}$ & $\mathbf{F}$ & Model (p) & $\mathbf{R}^{2}$ \\
\hline \multirow[b]{2}{*}{$\begin{array}{l}\text { Psychological } \\
\text { (Model 1) }\end{array}$} & \multirow{2}{*}{ General } & Invariant & 2,435 & 14,447 & 0,000 & \multirow[b]{2}{*}{55,058} & \multirow[b]{2}{*}{0,000} & \multirow[b]{2}{*}{0,188} \\
\hline & & $\begin{array}{lll}\begin{array}{l}\text { Parental } \\
\text { Total }\end{array} & \text { Social } & \text { Support- } \\
\end{array}$ & 0,015 & 7,42 & 0,000 & & & \\
\hline \multirow{3}{*}{$\begin{array}{l}\text { Psychological } \\
\text { (Model 2) }\end{array}$} & \multirow{3}{*}{ General } & Invariant & 0,193 & 0,746 & 0,456 & \multirow{3}{*}{92,933} & \multirow{3}{*}{0,000} & \multirow{3}{*}{0,44} \\
\hline & & $\begin{array}{l}\text { Parental Social Support- } \\
\text { Total }\end{array}$ & 0,008 & 4,277 & 0,000 & & & \\
\hline & & Self-esteem & 0,025 & 10,295 & 0,000 & & & \\
\hline
\end{tabular}

Source: Obtained from analysis of data. ${ }^{*} \mathrm{p}<0,05$

When Table 4 is examined, the regression analysis to determine the cause-effect relationship between the total of parental social support and the overall psychological resilience was found statistically significant in Model 1 $(\mathrm{F}=55,058 ; \mathrm{p}=0,000<0.05)$. As a determinant of the general level of psychological resilience, the relationship between the total variables of parental and social support (explanatory predictive power) was found to be weak $\left(\mathrm{R}^{2}=0.188\right)$. The total level of parental social support increases the overall level of psychological endurance $(\beta=0,015)$. In Model 2, self-esteem was added to the effect of parental social support on psychological resilience.

In Model 2, the regression analysis was performed to determine the cause-effect relationship between the total of social support, self-esteem and psychological resilience overall $(\mathrm{F}=92,933 ; \mathrm{p}=0,000<0.05)$. As a determinant of the general level of psychological resilience, the relationship between the total of parental social support and selfesteem variables (explanatory power) was found to be very strong $\left(\mathrm{R}^{2}=0,440\right)$. The total level of parental social support increases the overall level of psychological resilience $(\beta=0,008)$. The level of self-esteem increases the overall level of psychological resilience $(\beta=0,025)$. As a result of the hierarchical regression analysis, the addition of self-esteem to the model increased the rate of $\mathrm{R}^{2}$ from $18.8 \%$ to $44 \%$. It was found that parental social support and self-esteem increased their explanatory power among the determinants of psychological resilience.

\section{Results and Discussion}

4.1. Results and Discussion on the Relationship between Perceived Social Support, Self-Esteem and Psychological Resilience Levels of Parents Who Have Children with Special Educational Needs

In the study, there were positive relationships between the psychological resilience, perceived social support and self-esteem levels of the parents who had children with special educational needs. There is a moderate positive correlation between the general level of psychological resilience and self-esteem. There is a weak positive relationship between self-esteem and parental social support scores.

The findings of studies in the literature support the results of this study. Çakar-Savi and Karatas (2012) found that there was a positive correlation between self-esteem and perceived social support. Karatas and Cakar (2011) found that there was a positive correlation between self-esteem and psychological resilience. Güloğlu and Karairmak (2010) found a positive correlation between self-esteem and psychological resilience.

Karairmak (2006) referring to the study of Werner (1989) stated that the existence of social support network at school or in society was among the protective factors affecting psychological resilience. Gizir (2007) listed the high self-esteem, self-efficacy and self-esteem among other individual factors identified to be associated with psychological resilience. Chen (2017) investigated the relationship among emotional intelligence, perceived social 
support and psychological resilience. As a result of the study, the highest level of psychological resilience among the research groups of the individuals with high level of friend social support and emotional intelligence was determined as the group.

As a result of interviews with mothers who had children with mental deficiency, Gardner and Harmon (2002) listed the features that enable mothers to be psychologically resistant individuals. They expressed the benefit of social support among these features, Bayraklı (2010).

Altom (2010) examined the effect of perceived social support on the relationship between depression and selfesteem. A strong relationship was found between self-esteem and perceived social support. However, high selfesteem was associated with a high level of perceived social support.

The findings of studies in the literature are in the opposite direction of the results of this study. Saget-Menager (2010) investigated the impact of racial socialization and psychological resilience on self-esteem levels and selfesteem among different black groups in the United States. As a result of the research, it was concluded that there was a significant relationship between self-esteem and psychological resilience.

When the studies in the literature are examined, it is seen that many research results support the results of present study: there is a positive and significant relationship between perceived social support and psychological resilience. While some studies mention a strong relationship between perceived social support and psychological resilience, some studies have identified perceived social support as a source of psychological resilience.

When the studies in the literature are examined, it is seen that many research results support the results of present study: there is a positive and significant relationship between self-esteem and psychological resilience. The results of the research show that the level of self-esteem is affected by perceived social support level.

Although there is a lot of research supporting a positive and meaningful relationship between self-esteem and psychological resilience, in a study no significant relationship was found between self-esteem and psychological resilience.

In this study, when the relationship between psychological resilience sub-dimensions, perceived social support sub-dimensions and self-esteem were examined, a very weak positive relationship was found between the structured style, social competence, social resources which were sub-dimensions of psychological resilience and information support which was sub-dimension of perceived social support. This result reveals that parents' (who have children with special educational needs) perception of information support and their prioritization of information support should be considered.

Within the scope of the findings of the research, a significant positive correlation was found between the subdimensions of psychological resilience which were social resources and social competence, and sub-dimensions of perceived social support which were information support and emotional support. A significant very weak positive correlation was found between social competence and social cohesion support which was one of the sub-dimensions of perceived social support. According to these results, it is necessary to discuss the perception level of information support of the parents who have children with special educational needs, the sufficiency and meaning of the information support, and whether the parents have sufficient knowledge and belief in their relations with people. In the light of these results, another issue that needs to be addressed is the need to investigate how parents who have children with special educational needs position themselves in the community. Is the relationship between social competence, information support, and emotional support so poor as parents who have children with special educational needs isolate themselves from society? That is a question to consider.

When the relationship between self-esteem and psychological resilience sub-dimensions were examined, a moderate correlation was found between self-esteem and self-perception and planned future, and a weak correlation was found between self-esteem and structured style, social competence, family cohesion and social resources. This situation led to the consideration of self-esteem levels in the studies on the thoughts and self-perceptions of the parents who had children with special educational needs. There was a weak relationship between self-esteem and information support, social cohesion support, care support and emotional support which were the sub-dimensions of social support perception. This situation raises the question of whether the relationship between the external factors is less than the internal factors in the emergence of self-esteem.

\subsection{Results and Discussion on the Perceived Social Support Level as a Predictor of Psychological Resilience Level of Parents Who Have Children with Special Educational Needs}

As a predictor of the general level of psychological resilience, the relationship with the total variable of parental social support (explanatory power) was found to be weak. As the total level of parental social support of parent increases, the overall level of psychological resilience is increasing. When the literature was examined, it was seen that the researches of Bayraklı (2010); Carter (2014) and Zomerlei (2015) supported the results of the present study, but the research of Nguyen (2012) did not support.

Bayraklı (2010) in his research concluded that the quantity and quality of social support had a low and positive effect on psychological resilience. Carter (2014) stated that psychological resilience was an important predictor of social support and social support was an important predictor of psychological resilience. The related research supports the relationship between psychological resilience and perceived social support.

Nguyen (2012) aimed to improve the existing knowledge on psychological resilience in literature, examine the level of psychological resilience of the Resilience Scale for Adults, and investigate the effects of perceived social support on psychological resilience in a long dimension of life. The related research indicates that the effect of social support from spouses on psychological resilience has little or no effect.

In the research findings, it was found that there was an increasing effect of social cohesion support which was one of the sub-dimensions of social support perception in predicting self-perception, planned future, structured style, social competence, social resources and family cohesion which were the sub-dimensions psychological resilience, and there were no significant results in other sub-dimensions of social support perception.

The emergence of social cohesion support as a predictor of all sub-dimensions of the psychological resilience of the parents who had special educational needs revealed the necessity to discuss some questions. Why information support, emotional support and care support do not predict the psychological resilience sub-dimensions of the 
parents who have children with special educational needs? Why does social cohesion support predict the all subdimensions? This situation that causes us to ask these questions leads to this question: Do parents (who have children with special educational needs) firstly need people to share their experiences? If the psychological resilience of the parents who have children with special educational needs depends on the persons to whom take social cohesion support, it is an important issue to discuss how the characteristics of people should be.

\subsection{Results and Discussion on the Self-Esteem Level as a Predictor of Psychological Resilience Level of Parents Who Have Children with Special Educational Needs}

As a predictor of the general level of psychological resilience, its relationship with self-esteem variable was found to be strong. As the level of self-esteem of the parents increases, the general level of psychological resilience is increasing. In the literature, there are two researches that examined the effect of self-esteem as a predictor of psychological resilience, although there is no study on whether parents' self-esteem level predicts the psychological resilience of parents who have children with special educational needs. There are researches that support the results of present study (Karairmak, 2007) and do not support (Bumpus, 2014).

Karairmak (2007) in his research indirectly revealed the relationship between self-esteem and psychological resilience. The related research revealed that self-esteem influenced the variables affecting psychological resilience and indirectly self-esteem predicted psychological resilience.

Bumpus (2014) compared the racial belonging, psychological resilience, and self-esteem levels of adopted African-American individuals in another study that revealed data on the predictive power of self-esteem. In this research, a significant negative relationship was found between psychological resilience and self-esteem. The relevant research does not support the results of this study.

The self-esteem levels of the parents who have children with special educational needs strongly predict their levels of self-perception and planned future which are the sub-dimensions of psychological resilience. The selfesteem levels of the parents who have children with special educational needs weakly predict their structured style, social competence, family cohesion and social resources levels which are the sub-dimensions of psychological resilience. This reveals the importance of self-esteem and self-esteem in shaping the self-perceptions and planned future of the parents who have children with special educational needs.

\subsection{Results and Discussion on the Self-Esteem and Perceived Social Support Levels as Predictors of Psychological Resilience Levels of Parents Who Have Children with Special Educational Needs}

The levels of perceived social support and self-esteem levels of the parents were found to predict psychological resilience as a result of the regression analysis. As a result of the analyzes, it was revealed that predictive total levels of perceived social support and self-esteem levels on psychological resilience were higher than predictive individual levels of perceived social support and self-esteem levels on psychological resilience. The fact that selfesteem and perceived social support together create strong conditions in explaining psychological resilience necessitates consideration of other variables in explaining psychological resilience.

\section{References}

Altom, M.W., 2010. Moderating effects of social support in the relationship between self-esteem and depression. A Dissertation Submitted in Partial Fulfillment of the Requirements for the Degree of Doctor of Philosophy University of Washington.

Aricak, O.T., 1999. Development of self and vocational self-esteem through group counseling. Unpublished PhD Thesis. Marmara University Institute of Educational Sciences, İstanbul.

Aslan, C.C., 2010. Psychological symptoms of parents with mentally retarded children, social support perception and coping styles with stress. Master of Science Thesis, Maltepe University, Institute of Social Sciences, Department of Psychology, Istanbul.

Basim, H.N. and F. Cetin, 2011. The reliability and validity of the resilience scale for Adults-Turkish version. Turk Psikiyatri Derg, 22(2): 104-114.

Bayrakl, H., 2010. Examining the variables affecting the resilience of mothers with mentally retarded and non-disabled children. Unpublished Master's Thesis, Ankara University Ankara.

Bildirici, F., 2014. The relationship between family burden and psychological resilience in families with children with special education needs. Master Thesis, Haliç University Department of Psychology.

Bumpus, J.A., 2014. Transracial adoption: Racial identity, resilience, and self-esteem of African American adoptees. Submitted in Partial Fulfillment of the Requirements for the Degree of Doctor of Psychology in the Department of Clinical Psychology at Antioch University New England.

Çakar-Savi, F. and Z. Karatas, 2012. The self-esteem, perceived social support and hopelessness in adolescents: The structural equation modeling. Educational Sciences Theory \& Practice, 12(4): 2406-2412.

Carter, T.G., 2014. A correlational study of resilience and social support among national guard/reserve families. A Dissertation Presented in Partial Fulfillment Of the Requirements for the Degree Doctor of Philosophy, Capella University.

Cattık, M., 2015. The relationship between social support and self-efficacy levels of parents of children with developmental disabilities and life satisfaction levels. M.Sc., Anadolu University, Institute of Educational Sciences, Special Education.

Chen, S., 2017. Chinese adolescents' emotional intelligence, perceived social support, and resilience. Submitted to the faculty of the University Graduate School in Partial Fulfillment of the Requirements for the Degree Doctor of Philosophy in the School of Education, Indiana University.

Chrzanowski, G., 1981. The genesis and nature of self-esteem. American Journal of Psychotherapy, 35(1): 38-46. Available at: https://doi.org/10.1176/appi.psychotherapy.1981.35.1.38.

Coleman, J. and A. Hagell, 2007. The nature of risk and resilience in adolescence. Adolescence, risk and resilience. Against the Odds, 3: 2-16.

Demir, E., 2010. Comparison of self esteem and somatization levels in mothers of autistic children. Istanbul: Maltepe University, Institute of Social Sciences, Department of Psychology.

Fraser, M.W., M.J. Galinsky and J.M. Richman, 1999. Risk, protection, and resilience: Toward a conceptual framework for social work practice. Social Work Research, 23(3): 131-143. Available at: https://doi.org/10.1093/swr/23.3.131.

Friborg, O., D. Barlaug, M. Martinussen, J.H. Rosenvinge and O. Hjemdal, 2005. Resilience in relation to personality and intelligence. International Journal of Methods in Psychiatric Research, 14(1): 29-42. Available at: https://doi.org/10.1002/mpr.15.

Friborg, O., O. Hjemdal, J.H. Rosenvinge and M. Martinussen, 2003. A new rating scale for adult resilience: What are the central protective resources behind healthy adjustment? International Journal of Methods in Psychiatric Research, 12(2): 65-76. Available at: https://doi.org/10.1002/mpr.143.

Gardner, J. and T. Harmon, 2002. Exploring resilience from a parent's perspective: A qualitative study of six resilient mothers of children with an intellectual disability. Australian Social Work, 55(1): 60-68. Available at: https://doi.org/10.1046/j.0312407x.2002.00007.x. 
Garmezy, N., 1993. Children in poverty: Resilience despite risk. Psychiatry, 56(1): 127-136. Available at: https://doi.org/10.1080/00332747.1993.11024627.

Gizir, C.A., 2007. A review study on psychological strength, risk factors and protective factors. Turkish Journal of Psychological Counseling and Guidance, 3(28): 113-128.

Güloğlu, B. and Ö. Kararrmak, 2010. Self-esteem and psychological stability as a predictor of loneliness in university students. Ege University Faculty of Education Journal, 11(2): 73-88.

Guralnick, M.J., M.A. Hammond, B. Neville and R.T. Connor, 2008. The relationship between sources and functions of social support and dimensions of child-and parent-related stress. Journal of Intellectual Disability Research, 52(12): 1138-1154. Available at: https://doi.org/10.1111/j.1365-2788.2008.01073.x.

House, J.S., 1981. Social structure and personality. In M. Rosenberg \& R.H. Turner (Eds.), Social psychology. Sociological perspectives. New York: Basic Books. pp: 525-561.

Kaner, S., 2003. Family support scale: Factor structure, reliability and validity studies. Ankara University, Faculty of Educational Sciences Special Education Journal, 4(1): 57-72.

Kaner, S., 2010. Psychometric properties of revised maternal social support scale. Education and Science, 35(157): 15-29.

Kaner, S., H. Bayrakli and C.O. Guzeller, 2011. Investigation of parents' resilience perceptions in terms of some variables. Ankara University Faculty of Educational Sciences Special Education Journal, 12(2): 63-78.

Karairmak, Ö., 2006. Psychological strength, risk factors and protective factors. Turkish Journal of Psychological Counseling and Guidance, 3(26): 129-142.

Karaırmak, Ö., 2007. Investigation of personal qualities contributing to psychological resilience among earthquake survivors: A model testing study. Doktora Tezi, Ortadoğu Teknik Üniversitesi, Ankara.

Karatas, Z. and F.S. Cakar, 2011. Self-esteem and hopelessness, and resiliency: An exploratory study of adolescents in Turkey. International Education Studies, 4(4): 84-91. Available at: https://doi.org/10.5539/ies.v4n4p84.

Lambert, V.A., C.E. Lambert, G.L. Klipple and E.A. Mewshaw, 1989. Social support, hardiness and psychological well-being in women with arthritis image. The Journal of Nursing Scholarship, 21(3): 128-131. Available at: https://doi.org/10.1111/j.15475069.1989.tboo1 16.x.

Masten, A.S., 2001. Ordinary magic: Resilience processes in development. American Psychologist, 56(3): 227-238. Available at: https://doi.org/10.1037//0003-066x.56.3.227.

Masten, A.S. and M.J. Reed, 2002. Resilience in development. In C. R. Snyder, \& S. J. Lopez (Eds.), Handbook of Positive Psychology. New York: Oxford University Press. pp: 117-131.

Nguyen, C.H., 2012. Individual resilience, social support, and health risk behaviors in adolescents and young adults: Study on crosssectional and longitudinal samples. A Dissertation Submitted in Partial Fulfillment of the Requirements for the Degree of Doctor of Philosophy in Community Health Promotion, University of Arkansas.

Rutter, M., 2006. Implications of resilience concepts for scientific understanding. Annals of the New York Academy of Sciences, 1094(1): 112. Available at: https://doi.org/10.1196/annals.1376.002

Saban, F., 2010. Investigation of self-esteem and anxiety of children with and without mentally retarded brothers. Master Thesis, Ataturk University, Institute of Health Sciences, Department of Pediatrics, Erzurum, Turkey.

Saget-Menager, S., 2010. Black female adolescents' self-esteem: Effects of socialization and resilience. A Dissertation, Presented to the Faculty of the School of Psychology \& Counseling Regent University.

Sivrikaya, T., 2012. Family stress, detection of social support and family burden of mothers with mentally handicapped children. Master Thesis, Abant Izzet Baysal University, Institute of Educational Sciences, Department of Special Education, Bolu.

Ülker, T.G., 2012. Psychological persistence levels investigation of contact barriers of different university students. Master Thesis, Hacettepe University, Institute of Social Sciences, Department of Educational Sciences, Psychological Counseling and Guidance, Ankara.

Werner, E.E., 1989. High-risk children in young adulthood: A longitudinal study from birth to 32 years. American Journal of Orthopsychiatry, 59(1): 72-81. Available at: https://doi.org/10.1111/j.1939-0025.1989.tbo1636.x.

Yörükoğlu, A., 1987. Youth" mental health mental disorders. 4th Edn., Ankara: Turkey Isbank Cultural Publications.

Zomerlei, D.R., 2015. Family resilience following a diagnosis of pediatric cancer: Parent experiences of social support, coping, and adaption. A Dissertation Submitted to Michigan State University in Partial Fulfillment of the Requirements for the Degree of Human Development and Family Studies - Doctor of Philosophy. 